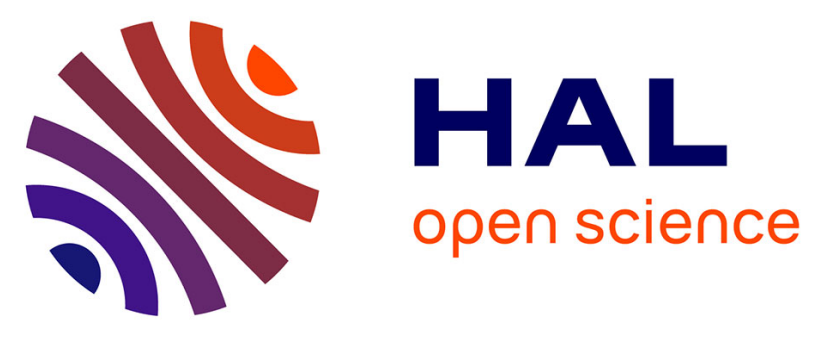

\title{
New model for assessing dose, dose rate, and temperature sensitivity of radiation-induced absorption in glasses
}

\author{
Olivier Gilard, Matthieu Caussanel, Hervé Duval, Gianandrea Quadri, \\ François Reynaud
}

\section{To cite this version:}

Olivier Gilard, Matthieu Caussanel, Hervé Duval, Gianandrea Quadri, François Reynaud. New model for assessing dose, dose rate, and temperature sensitivity of radiation-induced absorption in glasses. Journal of Applied Physics, 2010, 108 (9), pp.093115. 10.1063/1.3503370 . hal-01288493

\section{HAL Id: hal-01288493 \\ https://hal-univ-perp.archives-ouvertes.fr/hal-01288493}

Submitted on 15 Mar 2016

HAL is a multi-disciplinary open access archive for the deposit and dissemination of scientific research documents, whether they are published or not. The documents may come from teaching and research institutions in France or abroad, or from public or private research centers.
L'archive ouverte pluridisciplinaire HAL, est destinée au dépôt et à la diffusion de documents scientifiques de niveau recherche, publiés ou non, émanant des établissements d'enseignement et de recherche français ou étrangers, des laboratoires publics ou privés.

\section{(ㅇ)(1) $\$$}

Distributed under a Creative Commons Attribution - NonCommercial - NoDerivatives 44.0 


\section{New Model for Assessing Dose, Dose rate and Temperature Sensitivity of Radiation-Induced Absorption in Glasses}

Olivier Gilard ${ }^{\text {a) }}$

Centre National d'Etudes Spatiales, 18 Avenue E. Belin, 31401 Toulouse Cedex 4, France

Matthieu Caussanel

Laboratoire ELIAUS, Université de Perpignan Via Domitia, 52 Avenue Paul Alduy, 66860 Perpignan Cedex, France

Hervé Duval

Laboratoire ELIAUS, Université de Perpignan Via Domitia, 52 Avenue Paul Alduy, 66860 Perpignan Cedex, France

Gianandrea Quadri

Centre National d'Etudes Spatiales, 18 Avenue E. Belin, 31401 Toulouse Cedex 4, France

François Reynaud

Département photonique/IRO, Xlim UMR6172, 123 rue A. Thomas, 87060 Limoges cedex, France

${ }^{a)}$ Electronic mail : olivier.gilard@cnes.fr 


\section{Abstract}

A new theoretical approach is proposed to explain dose, dose rate and temperature sensitivity of Radiation-Induced Absorption (RIA) in glasses. In this paper a $\beta^{\text {th }}$-order dispersive kinetic model is used to simulate the growth of the color center density in irradiated glasses. This model yields an explanation of power-law dependency on dose and dose rate usually observed for optical fiber RIA. It also leads to an Arrhenius-like relationship between RIA and glass temperature during irradiation. With a very limited number of adjustable parameters, it succeeds in explaining, with a good agreement, RIA growth of two different optical fibes references over wide ranges of dose, dose rate and temperature. 


\section{INTRODUCTION}

Photonic systems get increasingly used within nuclear and space applications : data transfer equipments, imagers, spectrometers, dosimeters, temperature and pressure sensors, and gyroscopes. Most of these systems require glass-based devices such as optical fibers, couplers, filters, optical windows, etc. Therefore it is of considerable interest to assess the radiation sensitivity of such devices to identify which ones can reliably be used in a radiative environment. Radiation Induced Absorption (RIA) in glasses is a well known phenomenon that has been both theoretically ${ }^{1,2,3,4,5,6}$ and experimentally $y^{7,8,9,10,11,12,13}$ studied during the last decades. It results from color center generation which is due to hole and/or electron trapping by defect sites (either pre-existing in the material or radiation-induced). Usually RIA is considerably more intense towards shorter wavelengths ${ }^{11,12}$ and also strongly depends on dose-rate $^{2,11,12}$, temperature ${ }^{2}$, and doping species $^{11,12}$. Several approaches have already been proposed to model dose and dose rate effect on $\mathrm{RIA}^{1,2,3,4,5,6}$. However very few take into account the effect of glass temperature during the irradiation ${ }^{3}$. The RIA is usually fitted by power $^{2}$, stretched exponential ${ }^{14}$ or saturating-exponential ${ }^{15,16, \text { Erreur } ! \text { Source du renvoi introuvable., } 16}$ models relaying on first ${ }^{18}$, second ${ }^{9}$ or higher ${ }^{20,21,22}$-order kinetics. Another approach based on Linear and Time-Invariant (LTI) system theory has been tested on Ge doped fibers ${ }^{23,24}$ : the power law obtained from the fiber radiation impulse response fairly matchs RIA growth and recovery. Basically all these models assume that two antagonist mechanisms control RIA growth : the first one related to the generation of color centers, and the second one to their annihilation (i.e. recombination). Recombination rate is usually considered as constant over time. In this study we propose to use a more general formalism based on a $\beta^{\text {th }}$-order dispersive kinetic equation including temperature effect. The term "dispersive" means that color center recombination rate can depend on time assuming that recombination mechanisms are related to diffusion limited processes. This kind of diffusion limited phenomenon is very widespread in condensed media and is often successfully described by such a dispersive kinetic 
formalism $^{25}$. The proposed model and the underlying mathematics are described in section II. Then section III is devoted to evaluate its correctness by testing it against experimental RIA growth curves.

\section{DISPERSIVE KINETIC MODEL}

The present model relies on the crude approximation that a single dominant color center is responsible for RIA. We will see later that this assumption, treated in the dispersive kinetic scheme, is sufficient to explain the power-law dependence on dose and dose rate usually observed on optical fibers RIA roughly up to 100 krads for Ge-doped silica core fibers. The proposed model assumes that electrons and holes generated during irradiation can be trapped on pre-existing defects forming the color centers responsible for the RIA. In the meantime, it is also assumed that a thermal de-trapping can occur with a time-dependent reaction rate coefficient (dispersive kinetics).

\section{A. First-order kinetics}

In a first-order dispersive kinetic scheme, it is assumed that color center density evolution obeys to

$$
\frac{d n}{d t}=g N_{p} \dot{D}-\frac{\alpha}{\tau^{\alpha}} t^{\alpha-1} n
$$

where $n$ is the color center density, $N_{p}$ the pre-existing defect density, $\dot{D}$ the dose rate, $\alpha$ is a number between 0 and $1, \tau$ is the characteristic decay time, $t$ is the irradiation time and $g$ is a constant. The first term on the right side of Eq. (1), $g N_{p} \dot{D}$, is related to the generation of color centers while the second one, $-\frac{\alpha}{\tau^{\alpha}} t^{\alpha-1} n$, corresponds to their annihilation ${ }^{5,25}$.

To solve this equation we first perform the following variable change $\mu=\left(\frac{t}{\tau}\right)^{\alpha}$. Equation (1) becomes 
$\frac{d n}{d \mu}=N_{p} \dot{D} g \frac{\mu^{\frac{1-\alpha}{\alpha}} \tau}{\alpha}-n$

The solution of the associated homogeneous equation is $n=K e^{-\mu}$ where $K$ is an integration constant. Assuming that $n(\mu)=K(\mu) e^{-\mu}$ is solution of Eq. (2) (constant variation method), we have

$$
\frac{d K}{d \mu}=N_{p} \dot{D} g \frac{\mu^{\frac{1-\alpha}{\alpha}} \tau e^{\mu}}{\alpha}
$$

By replacing $e^{\mu}$ by its Maclaurin expansion and integrating Eq. (3), we obtain

$$
K=\frac{N_{p} \dot{D} g \tau}{\alpha} \sum_{i=0}^{+\infty} \frac{\mu^{i+\frac{1}{\alpha}}}{i !\left(i+\frac{1}{\alpha}\right)}
$$

Thus, the general solution of Eq. (1), assuming that $n(0)=0$, is given by

$$
n=\frac{N_{p} \dot{D} g \tau e^{-\left(\frac{t}{\tau}\right)^{\alpha}}}{\alpha} \sum_{i=0}^{+\infty} \frac{\left(\frac{t}{\tau}\right)^{i \alpha+1}}{i !\left(i+\frac{1}{\alpha}\right)}
$$

It is of interest to analyze two asymptotic limits of Eq. (5)

- when $t \rightarrow 0$

$$
n=N_{p} \dot{D} g t
$$

- when $t \rightarrow+\infty$

Equation (5) can be written as

$$
n=\frac{N_{p} \dot{D} g \tau e^{-\left(\frac{t}{\tau}\right)^{\alpha}}}{\alpha}\left(\frac{t}{\tau}\right)^{1-\alpha} \sum_{i=1}^{+\infty} \frac{\left(\frac{t}{\tau}\right)^{i \alpha}}{i !\left(1-\frac{1}{i}+\frac{1}{\alpha i}\right)}
$$

When $t \rightarrow+\infty$ this series converges for large values of $i$ and the term $\left(1-\frac{1}{i}+\frac{1}{\alpha i}\right)$ becomes therefore close to 1 . It results in 
$n=\frac{N_{p} \dot{D} g \tau e^{-\left(\frac{t}{\tau}\right)^{\alpha}}}{\alpha}\left(\frac{t}{\tau}\right)^{1-\alpha}\left(e^{\left(\frac{t}{\tau}\right)^{\alpha}}-1\right) \approx \frac{N_{p} \dot{D} g \tau}{\alpha}\left(\frac{t}{\tau}\right)^{1-\alpha}$

The characteristic time for which the transition between the $t \rightarrow 0$ and the $t \rightarrow+\infty$ solutions occurred is deduced by equating Eq. (6) and (8).

$$
t_{c}=\frac{\tau}{\alpha^{\frac{1}{\alpha}}}
$$

The approximated solution of Eq. (1) is, therefore, given by

$$
n=N_{p} \dot{D} g t\left(1-H\left(t-t_{c}\right)\right)+\frac{N_{p} \dot{D} g \tau}{\alpha}\left(\frac{t}{\tau}\right)^{1-\alpha} H\left(t-t_{c}\right)
$$

where $H$ is the Heaviside function.

Taking into account that $t=\frac{D}{\dot{D}}$, we have

$$
n=N_{p} g D\left(1-H\left(\frac{D}{\dot{D}}-t_{c}\right)\right)+\frac{N_{p} \tau^{\alpha} g}{\alpha} \dot{D}^{\alpha} D^{1-\alpha} H\left(\frac{D}{\dot{D}}-t_{c}\right)
$$

\section{B. $\beta^{\text {th }}$-order kinetics}

At this stage it is necessary to generalize the approach presented in the previous section to higher-order kinetics. Indeed, as mentioned in Refs. 2, 5, 9 19, 20 and 21, the growth of the induced absorption may follow kinetics of order greater than unity (bimolecular kinetics for instance). For $\beta^{\text {th }}$-order kinetics, color center density evolution equation is given by

$$
\frac{d n}{d t}=g N_{p} \dot{D}-\frac{\alpha}{\tau^{\alpha}} t^{\alpha-1} n^{\beta}
$$

where the kinetic order $\beta$ should be greater than 1 .

A simple analytic solution of such a differential equation would be difficult nay impossible to achieve. However results obtained for the first-order kinetic equation can help 
us to calculate an approximated solution of Eq. (12). We postulate that such an approximated solution could be written as

$n=A t\left(1-H\left(t-t_{c, \beta}\right)\right)+B t^{C} H\left(t-t_{c, \beta}\right)$

where $\mathrm{A}, \mathrm{B}, \mathrm{C}$ and $t_{c, \beta}$ are constants to be determined.

We first consider the case $t<t_{c, \beta}$. Using (12) and (13), we have

$A=g N_{p} \dot{D}-\frac{\alpha}{\tau^{\alpha}} t^{\alpha-1+\beta} A^{\beta}$

Accounting for the variation ranges of $\alpha$ (between 0 and 1) and $\beta$ (greater than 1 ), we obtain $\alpha-1+\beta>0$. This means that the term $\frac{\alpha}{\tau^{\alpha}} t^{\alpha-1+\beta} A^{\beta} \rightarrow 0$ when $t \rightarrow 0$. Thus, according to Eq. (14) the $A$ coefficient should be equal to $g N_{p} \dot{D}$.

Considering now the case $t>t_{c, \beta}$, using (12) and (13) we have

$B C t^{C-1}=g N_{p} \dot{D}-\frac{\alpha}{\tau^{\alpha}} t^{\alpha-1+\beta C} B^{\beta}$

If $C-1<0$ then the left-end term of (15) tends to zero when $t \rightarrow+\infty$. Taking into account that (15) should be verified whatever $t$ is (provided that $t$ is large enough), we should have $\alpha-1+\beta C=0$ and thus $C=\frac{1-\alpha}{\beta}$. It is worth to notice that this value ensures the condition $C-1<0$. Coming back to $(15)$, we have $B=\left(\frac{g N_{p} \dot{D}}{\alpha}\right)^{\frac{1}{\beta}} \tau^{\frac{\alpha}{\beta}}$.

The approximated solution of Eq. (12) is therefore given by 
$n=g N_{p} \dot{D} t\left(1-H\left(t-t_{c, \beta}\right)\right)+\left(g \frac{N_{p} \dot{D}}{\alpha}\right)^{\frac{1}{\beta}} \tau^{\frac{\alpha}{\beta}} t^{\frac{1-\alpha}{\beta}} H\left(t-t_{c, \beta}\right)$

Considering Eq. (16), it is trivial to determine $t_{c, \beta}$. We have

$t_{c, \beta}=\left[\left(g N_{p} \dot{D}\right)^{\frac{\beta-1}{\beta}} \alpha^{\frac{1}{\beta}}\left(\frac{1}{\tau}\right)^{\frac{\alpha}{\beta}}\right]^{\frac{\beta}{1-\alpha-\beta}}$

Replacing $t$ by $\frac{D}{\dot{D}}$ in (16) we obtain

$n=g N_{p} D\left(1-H\left(\frac{D}{\dot{D}}-t_{c, \beta}\right)\right)+\left(\frac{g N_{p}}{\alpha}\right)^{\frac{1}{\beta}} \tau^{\frac{\alpha}{\beta}} \dot{D}^{\frac{\alpha}{\beta}} D^{\frac{1-\alpha}{\beta}} H\left(\frac{D}{\dot{D}}-t_{c, \beta}\right)$

One can verify that Eq. (18) is equal to Eq. (11) if $\beta=1$.

To check the validity of Eq. (16) as an approximated solution of (12), results obtained by solving numerically Eq. (12) were compared to results obtained with the analytic relationship (16). Figure 1 illustrates this comparison that was performed for two sets of parameters $g N_{p} \dot{D}, \tau, \alpha$ and $\beta$. We observe an excellent agreement between numerical and analytic solutions that proves the correctness of our approach.

At this stage it is important to note that Eq. (18) differs substantially from the RIA growth models already published by Griscom ${ }^{5}$ for first- and second-order kinetics. Although the dispersive formalism was also used by Griscom, the power-law limits proposed by the author for first- and second-order growth kinetics is found to be equal to $N_{p}(g D)^{\alpha}$ when using our notations. This last equation appears to be independent of dose rate in contradiction with experiment. This is the reason why the author empirically modified his model by postulating that the $g$ coefficient is dose rate dependent. Equation (18) clearly shows that this 
assumption is not necessary since the solution proposed in the present work is naturally dependent on dose rate.

\section{Effect of the temperature}

The characteristic decay time in Eqs. (1) and (2) is related to the activation energy $E_{a}$ associated to color center recombination mechanism according to 25

$$
\frac{1}{\tau}=v^{\frac{-E_{a}}{k_{B} T}}
$$

where $v$ is a frequency factor, $k_{B}$ the Boltzmann constant and $T$ the absolute temperature.

By inserting the last equation in Eq. (18) we find

$$
n=g N_{p} D\left(1-H\left(\frac{D}{\dot{D}}-t_{c, \beta}\right)\right)+\left(\frac{g N_{p}}{\alpha}\right)^{\frac{1}{\beta}} v^{\frac{-\alpha}{\beta}} e^{\frac{\alpha E_{a}}{\beta k_{B} T}} \dot{D}^{\frac{\alpha}{\beta}} D^{\frac{1-\alpha}{\beta}} H\left(\frac{D}{\dot{D}}-t_{c, \beta}\right)
$$

\section{MODEL ASSESMENT}

In this section the second term of Eq. (20) is used to fit experimental RIA growth curves (this supposes that $\frac{D}{\dot{D}}>t_{c, \beta}$ ). Assuming that the RIA, $A$, is proportional to color center density, one obtains

$$
A=C e^{\frac{\alpha E_{a}}{\beta k_{B} T}} \dot{D}^{\frac{\alpha}{\beta}} D^{\frac{1-\alpha}{\beta}}
$$

where $C$ is a constant.

It is worth to notice that Eq. (21) has a mathematical form which is very convenient for fitting experimental data. It also facilitates growth result extrapolation to doses, dose rates and even temperatures outside the ones employed in the experiment.

To test the accuracy of the model we first used experimental data previously published by Griscom et al. $^{2}$ on a Ge-doped-silica-core optical fiber. Figures 2 (a) and (b) show the growth of the $\gamma$-ray-induced losses in Spectran SG320R multimode fibers characterized at $1310 \mathrm{~nm}$ for various dose-rates and temperatures. In these figures we have also reported least 
squares fitting results used to determine (from Eq. (21)) the model adjustable parameters (i.e. $C, \alpha, \beta$ and $E_{a}$ ). We observe a good agreement between adjusted and experimental data for the following values $C=1.3 \times 10^{-6}, \alpha=0.1, \beta=1.3$ and $E_{a}=2.8 \mathrm{eV}$. Quite similar activation energy values have been noticed from $\mathrm{GeO}_{2}$ irradiated glasses ${ }^{26,27}$.

A second set of data has also been analyzed. It comes from results of $\gamma$-ray irradiations carried out on several samples of Ge-doped single mode fiber provided by Draka. Figure 3 shows the RIA measured at $1310 \mathrm{~nm}$ for various dose rates. Irradiations were performed at room temperature. Data with the two lowest dose rates come from the present study, the other ones were already published by Wijnands et al. ${ }^{13}$. The adjusted parameters are $C=0.7, \alpha=0.41$ and $\beta=1$. We observe an excellent agreement up to 100 krads. Above this value, a saturation occurs and cannot be described by such a simple power-law model. This saturating behavior could possibly be modeled by summing the contribution of several individual color centers whose evolution law is given by Eq. (20). This approach was already proposed by Griscom at al. ${ }^{2}$ for simple saturating exponentials. However, as discussed below, this approach leads to other difficulties.

To assess the possibility to use the model to extrapolate the RIA outside the domain covered by experiments, we have voluntarily limited the set of experimental data used for least-square fitting to the four highest dose rates. Having done that, the model was used to predict the RIA for the two lowest dose rates at a total dose of 480 rads. Results are shown in Fig. (4). Here again we observe a very good agreement between predicted values and experimental ones.

It is clear that the present model is somewhat simplistic in a number of ways. For instance, its does not account for the fact that several color center populations can contribute to the optical losses measured at a given wavelength. However deconstructions of power-law growth curves into a summation of several color center contributions, as proposed by Griscom et al. ${ }^{2}$, are difficult to manage especially when temperature effect has to be considered. When 
using this kind of deconstruction methodology several hypotheses have to be made implicitly. For instance, the number of color center populations has to be fixed arbitrarily as well as the values of the color center production rate constants for the different populations. To be easily used, a model including more physical effects necessarily includes either more ad hoc hypothesis or more adjustable parameters. As mentioned by Williams et al. ${ }^{3}$ care must be taken to ensure that improved agreement with experimental data is not simply a result of more free parameters in the model. The approach presented in this paper seems to be a reasonable compromise (at least under $100 \mathrm{krad}$ ) between physics and a practical use of the model.

\section{CONCLUSION}

General solutions have been proposed to describe the growth of the RIA in glasses as a function of dose, dose rate and temperature. This model relies on the hypothesis that a single dominant color center is responsible for the measured RIA. We demonstrated that this assumption, treated in the dispersive kinetic scheme, is sufficient to explain the power-laws dependency on dose and dose rate usually observed on optical fibers RIA. The model leads to a very simple relationship between dose, dose rate and temperature making it very convenient to use for data fitting and extrapolation purposes. We have then verified the consistency of the model with experimental data obtained on two references of optical fiber over wide ranges of dose, dose rate and temperature.

\section{ACKNOWLEDGMENTS}

The authors would like to thank E. Burov, from Draka, for helpfull discussions. 


\section{References}

1 Y. Morita and W. Kawakami, IEEE Trans. Nucl. Sci. 36, 584 (1989).

2 D.L. Griscom, M. E. Gingerich, and J. Friebele, Phys. Rev. Lett. 71, 1019 (1993).

3 G.M. Williams, B.M. Wright, W.D. Mack and J. Friebele, Proc. SPIE, 3848, 271 (1999).

4 V.A. Mashkov, Wm. R. Austin, L. Zhang and R.G. Leisure, Phys. Rev. Lett. 76, 2926 (1996).

5 D.L. Griscom, Phys. Rev. B, 64, 174201 (2001).

6 P. Borgermans and B. Brichard, IEEE Trans. Nucl. Sci. 49, 1439 (2002).

7 B.D. Evans and G.H. Sigel, IEEE Trans. Nucl. Sci. 22, 2462 (1975).

8 E.J. Friebele, K. Long, C. Askins, M. Gingerich, M. Marrone, and D. Griscom, Proc. SPIE, 541, 70 (1985).

9 H. Henschel and E. Baumann, J. Lightw. Technol., 14, 724, (1996).

10 M.N. Ott, Proc. SPIE, 3440, 37 (1998).

11 S. Girard, J. Baggio, and J. Bisutti, IEEE Trans. Nucl. Sci. 53, 3750 (2006).

12 E. Regnier, I. Flammer, S. Girard, F. Gooijer, F. Achten, and G. Kuyt IEEE Trans. Nucl. Sci. 54, 1115 (2007).

13 T. Wijnands, L.K. De Jonge, J. Kuhnhenn, S.K. Hoeffgen, and U. Weinand, IEEE Trans. Nucl. Sci. 55, 2216 (2008).

14 R.A.B. Devine, Nuclear Instruments and Methods in Physics Research Section B: Beam Interactions with Materials and Atoms, Vol. 46, Issues 1-4, Pages 261-264, 1990

15 G.M. Williams, M.A. Putnam, E.J. Friebele, Proceedings of SPIE - The International Society for Optical Engineering, Vol. 2811, pp. 30-37, 1996

16 E.H. Friebele, D.L. Griscom, Treatise on material science and technology, Vol. 17, Glass II, edited by M. Tomozawa et R.H. Doremus, Academic Press, 1979

17 M. Kyoto, Y. Chigusa, M. Ohe et al., Journal of Lightwave Technology, Vol. 10, Nº3, pp. 289-294, 1992 
18 P.W. Levy, SPIE, Vol. 541, pp. 2-24, 1985

19 H. Imai, H. Hirashima, Journal of Non-Crystalline Solids, Vol. 179, pp. 202-213, 1994

20 E.J. Friebele, M.E. Gingerich, D.L. Griscom, SPIE, Vol. 1791, pp. 177-188, 1992

21 J.D.O. McFadden, R. Greenwell, J. Hatch et al., SPIE, Vol. 2811, pp. 77-94, 1996

22 P.W. Marshall, C.J. Dale, E.J. Friebele, K.A. Label, SPIE, Vol. C.R. 50, pp. 189-231, 1994

${ }^{23}$ D.T.H Liu, A.R. Johnston, Optics Letters, Vol. 19, N8, pp. 548-550, 1994

${ }^{24}$ R.H. West, Radiation and Its Effects on Components and Systems (Fifth European Conference on), RADECS, pp. 483-490, 1999.

25 A. Plonka, "Dispersive kinetics”, Kluwer Academic Publishers, Dordrecht, (2001).

${ }^{26}$ R.H. Magruder III, J.M. Jackson et al., Radiation Effects and Defects in Solids, Vol. 112, pp. 69-76, 1990

${ }^{27}$ M. Ohama, T. Fujiwara, A.J. Ikushima, App. Phys. L., Vol. 73, Nº11, 1998 


\section{Figures Captions}

FIG. 1 : Comparison of numerical and analytic solutions of Eq. (12).

FIG. 2 : Growth of the induced loss at various dose rates (a) and temperatures (b) (from Griscom et al. ${ }^{2}$ ), together with power-law fits based on Eq. (21).

FIG. 3 : Growth of the induced loss at various dose rate and associated power-law fits based on Eq. (21). Irradiations were carried out at room temperature. The data for the two lowest dose rates are from the present study, the other ones are from Wijnands et al. ${ }^{13}$. The induced loss is characterized at $1310 \mathrm{~nm}$.

FIG. 4 : Experimental, fitted and extrapolated induced loss measured at 480 rads as a function of dose rate. The induced loss is characterized at $1310 \mathrm{~nm}$. 


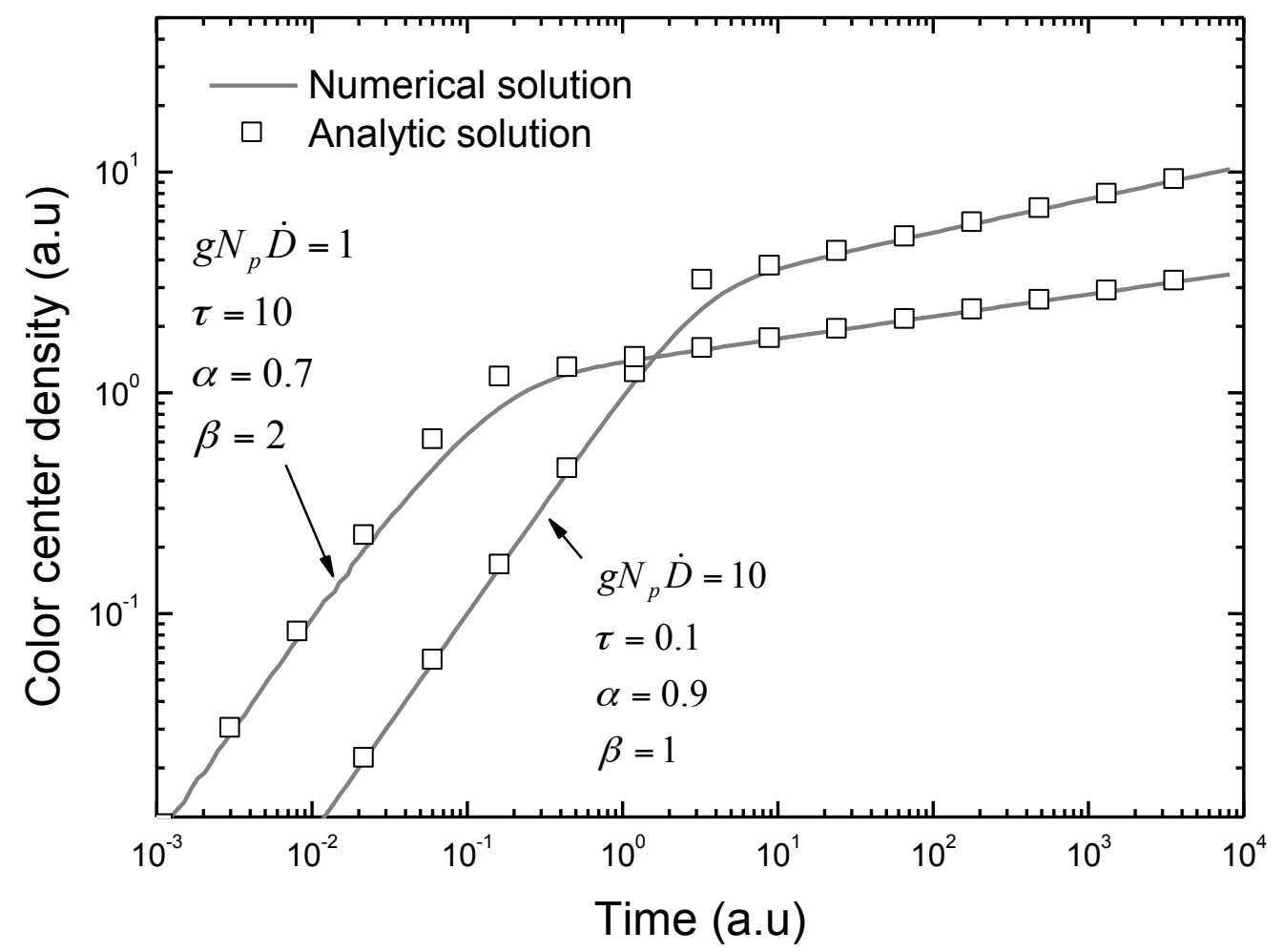

Fig. 1. 


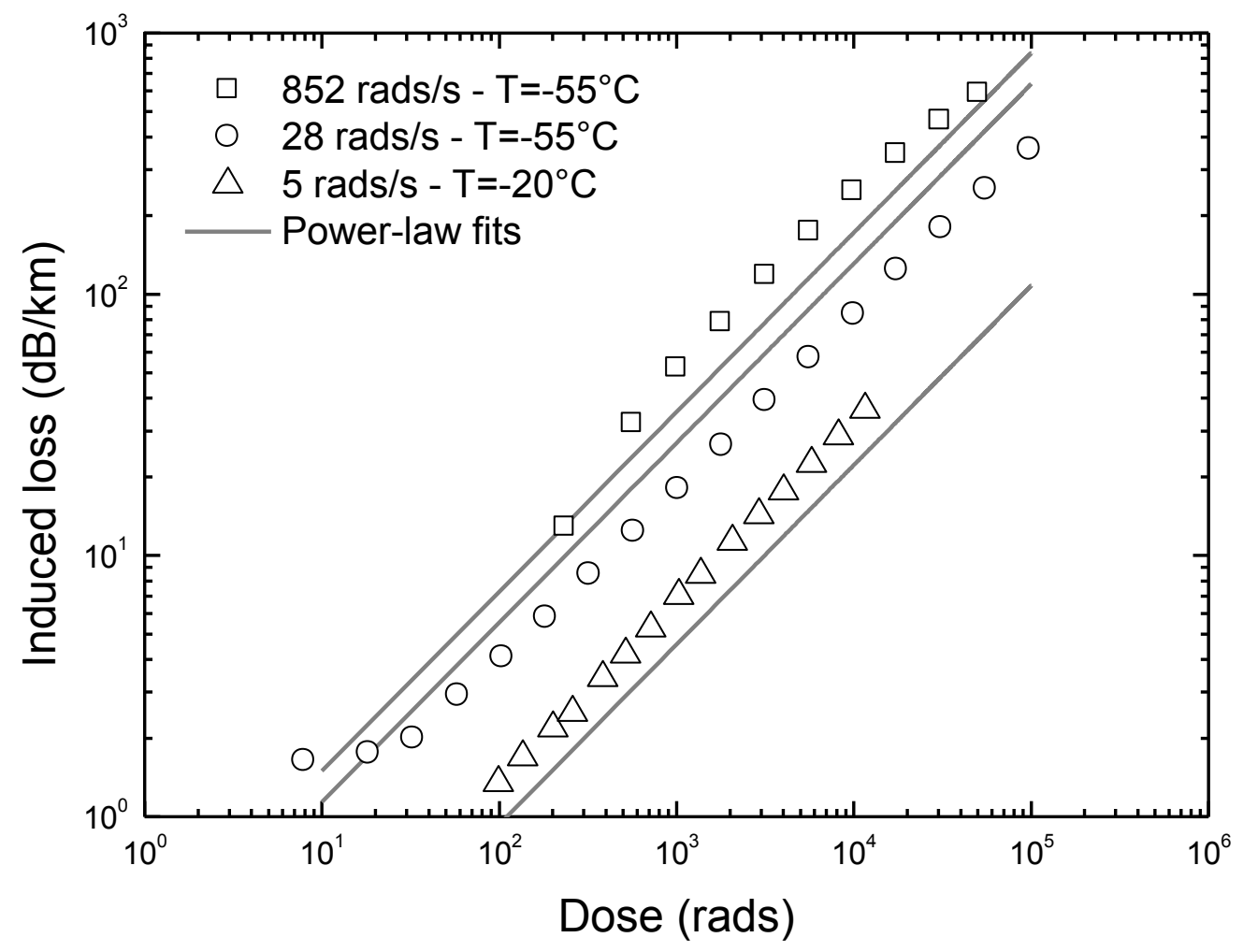

Fig. 2 (a). 


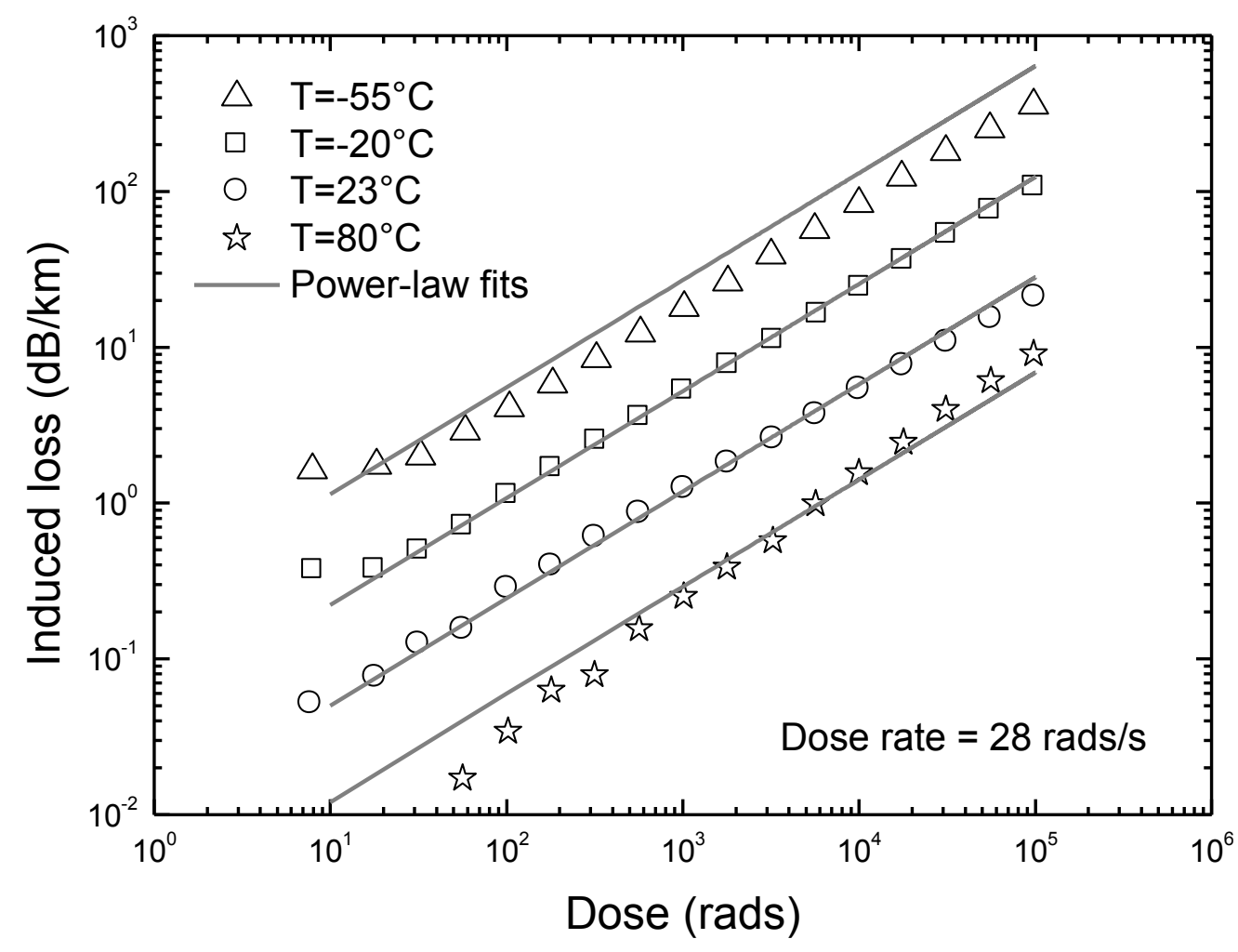

Fig. 2 (b). 


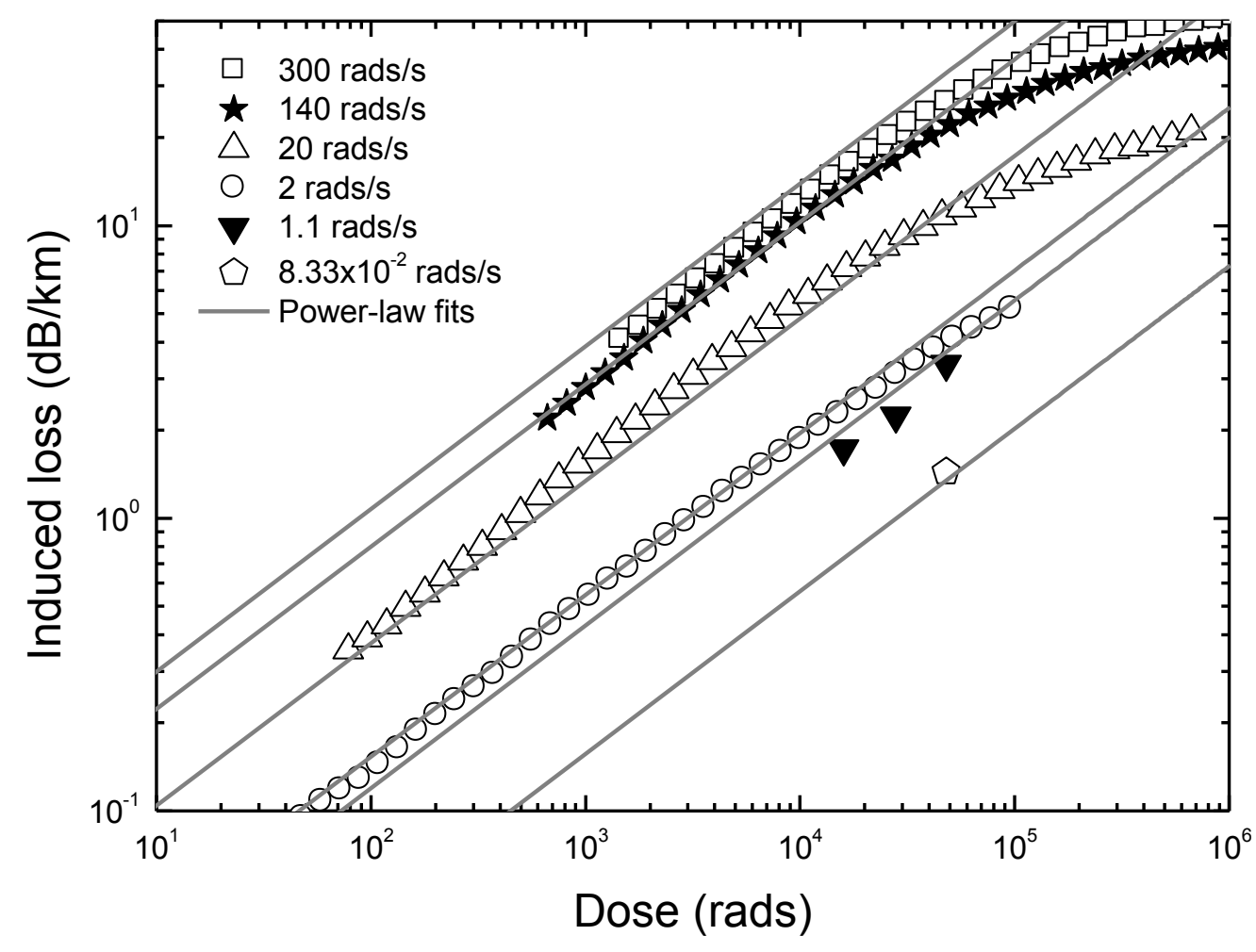

Fig. 3. 


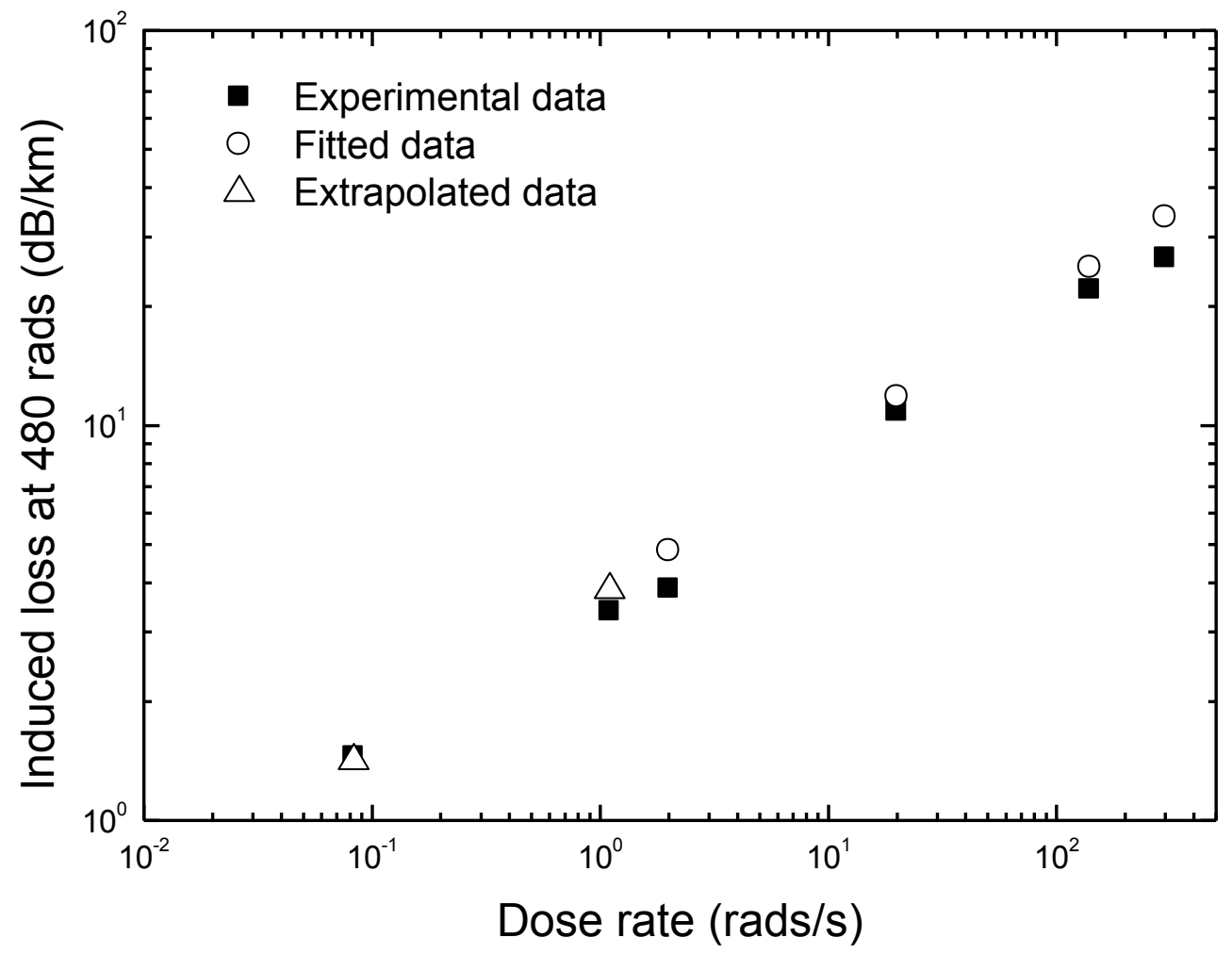

Fig. 4. 